\title{
Porous Surface State Analysis of Anodized Titanium for Biomedical Applications
}

\author{
J. JAKUBOWICZ, G. ADAMEK, and L. SMARDZ
}

In this work, pure Ti was anodically oxidized using $1 \mathrm{M} \mathrm{H}_{3} \mathrm{PO}_{4}+2-10$ pet $\mathrm{HF}$ electrolytes at 10 $\mathrm{V} v s$ open circuit potential (OCP). The structure of the anodized samples' surfaces was investigated using X-ray diffraction (XRD), X-ray photoelectron spectroscopy (XPS), atomic force microscopy (AFM), and scanning electron microscopy (SEM). The results show the presence of titanium dioxide $\left(\mathrm{TiO}_{2}\right)$ and titanium hydrogen phosphate $\left(\mathrm{Ti}\left(\mathrm{HPO}_{4}\right)_{2}\right)$ in the surface layer. Due to the chemical composition and properties that the materials have, they do not pose a threat and support the osseointegration process. The rough and porous anodic oxide morphology shown by the AFM is useful for tissue growth, as well as for improving corrosion resistance. The XPS confirms that the short anodization results in thin anatase-type $\mathrm{TiO}_{2}$, which is a candidate for hard tissue implant applications. The corrosion is improved after oxidation in $1 \mathrm{M} \mathrm{H}_{3} \mathrm{PO}_{4}+2$ pct $\mathrm{HF}$ electrolyte for 15 minutes. The wetting analysis shows hydrophilic properties and suggests good bioadhesion of the anodically oxidized surface. The surface supports osteoblast cell proliferation, indicating that the material has a surface state appropriate for hard tissue implant applications.

https://doi.org/10.1007/s11661-021-06492-2

(C) The Author(s) 2021

\section{INTRODUCTION}

TITANIUM is a basic and the most commonly used metal implant material for hard tissue applications. ${ }^{[1-3]}$ Titanium and its alloys provide mechanical properties for good cooperation with bone. A relatively low Young's modulus of the Ti reduces the stress shielding at the implant/bone interface. ${ }^{[4]}$ Titanium spontaneously oxidizes in contact with air, forming relatively thin $(<10$ $\mathrm{nm}$ ) but protective native titanium oxides. The thickness of the oxides can be enlarged through application of different surface treatments. ${ }^{[5-7]}$ The native or artificial titanium oxides, which are present on the surface, passivate the surface and provide high corrosion resistance and biocompatibility.

Taking into account the contact of the metallic implant with tissue, surface treatment plays a crucial role for good implant biocompatibility and osseointegration. ${ }^{[8-10]}$ So, in recent years, many works related to biomaterials have concentrated on surface improvements. ${ }^{[11-16]}$

J. JAKUBOWICZ and G. ADAMEK are with the Institute of Materials Science and Engineering, Poznan University of Technology, 61-138 Poznan, Poland. Contact email: jaroslaw.jakubowicz@put.poznan.pl L. SMARDZ is with the Institute of Molecular Physics, Polish Academy of Sciences, 60-179 Poznan, Poland.

Manuscript submitted on July 2, 2021; accepted October 8, 2021.

Article published online November 8, 2021
Electrochemical treatment ${ }^{[17-19]}$ is one of the ways to provide the following:

(1) good corrosion resistance and biocompatibility-due to the formation of thick protective titanium oxide, and

(2) good osseointegration - due to the formation of the rough/porous surface of desired wettability.

The rough surface of the implant has an effect on wettability and stimulates cell attachment and their proliferation. ${ }^{[20]}$ A thicker artificial anodic oxide, in comparison to a native oxide, provides a more useful and effective barrier against releasing harmful compounds (e.g., corrosion products or ions of toxic elements) from the implant into the body, and vice versa - from the body and its fluids into the implant. The chemical composition of the surface layer is important too because it may have an effect on the cell growth or dying.

One of the best methods of surface modification is anodic oxidation. ${ }^{[17-19]}$ It is commonly accepted that the anodic oxidation is usually made in $\mathrm{a}_{3} \mathrm{PO}_{4}$ and $\mathrm{HF}$ electrolyte mixture. ${ }^{[11,21]}$ Since $\mathrm{H}_{3} \mathrm{PO}_{4}$ is an effective oxidation agent, and $\mathrm{HF}$ is a surface etchant, the electrolyte, which has a suitable ratio of $\mathrm{H}_{3} \mathrm{PO}_{4}$ to $\mathrm{HF}$, provides a balance between oxide formation and its dissolution, giving a surface with suitable composition and morphology. The balance between electrolyte composition and oxidation conditions has an effect on the surface state and results in the formation of a continuous oxide layer or a layer that consists of pits, pores, or 
nanotubes enlarging the surface roughness, which differentiate and enhance its biocompatibility. ${ }^{[9]}$ For example, Das et al. ${ }^{[1]}$ investigated cell attachment and proliferation on $\mathrm{Ti}$ oxidized in different electrolytes. They found that osteoblast cells grow preferentially after treatment in $\mathrm{H}_{3} \mathrm{PO}_{4}$, significantly better than in $\mathrm{HF}$ and $\mathrm{H}_{2} \mathrm{SO}_{4}$. So, $\mathrm{H}_{3} \mathrm{PO}_{4}$ is the most promising agent in the surface biofunctionalization using the electrochemical method. In this electrolyte, the $\mathrm{PO}_{4}{ }^{3-}$ ions may play a key role, as they control roughness, wettability, and surface energy. ${ }^{[11]}$

Anodic oxidation to improve titanium surface biofunctionality is mainly carried out bidirectionally to obtain rough surfaces with pits/pores or alternatively to obtain $\mathrm{TiO}_{2}$ nanotubes. Both types of surfaces are useful, although those with nanotubes can lead to an additional benefit in the nanoscale biofunctionalized surface. It is commonly accepted that growth of various bone cells is supported by surface features of various dimensions, from nano- to micrometer. ${ }^{[22,23]}$ For example, the nanostructured features of the surface support adhesion of osteoblasts, while they reduce adhesion of fibroblasts and endothelial cells. ${ }^{[22,24]}$ Deposition of calcium in the osseointegration process on a nanostructured titanium surface is three times faster than on its conventional microcrystalline counterpart. ${ }^{[22,24]}$ Even though anodic oxidation has been studied extensively for years, the process is still worthy of further investigation as it broadens knowledge of the surface state after the process.

The main goals of this work were to expand our knowledge and to find correlation between selected anodization conditions and the formed surface, which should present high potential for implant application. The titanium surface biofunctionalization, through application of anodic oxidations, is a relatively easy and effective process that provides a biocompatible tissue growth supporting surface. Different variants of electrochemical treatment, including the type of electrolyte, its chemical composition, and the current conditions, make it difficult to interpret and compare the results. For the correct assessment of results obtained, a number of tests should be carried out, including studies on structure and physicochemical properties. In our work, the basic component was $1 \mathrm{M} \mathrm{H}_{3} \mathrm{PO}_{4}$ used as an electrolyte, which was modified by adding varying $\mathrm{HF}$ contents to accelerate surface changes. In this work, we focus on the various amounts of HF-oxidation accelerator as the key factor of anodic oxidation for appropriate Ti-surface biofunctionalization. Consequently, we show the effect of anodic Ti oxidation on the surface properties related to biomedical applications, and the obtained results make it possible to gain new insights into titanium surface biofunctionalization.

\section{EXPERIMENTAL DETAILS}

Commercially pure $\mathrm{Ti}$ in the form of foil (Grade 2, ASTM B265, 0.125-mm thick, and $\geq 99.6$ pet purity) from Goodfellow was electrochemically oxidized using a Solartron 1285 potentiostat. Prior to anodization, the Ti foil was degreased by sonicating in acetone and methanol, rinsed in water, and dried in nitrogen stream.
The samples with an active surface of $1.5 \mathrm{~cm}^{2}$ were anodically oxidized in a homemade electrochemical Teflon cell with $\mathrm{Ti}$ as the working electrode, $\mathrm{Pt}$ as the counter electrode, and $\mathrm{Pt}$ as the reference electrode. The process was done for 15 minutes in $1 \mathrm{M} \mathrm{H}_{3} \mathrm{PO}_{4}$ distilled water-based electrolyte containing 2, 5, and 10 pct HF. The electrochemical treatment starts by voltage jumping from the open circuit potential (OCP) to constant $10 \mathrm{~V}$ $v s$ OCP and keeping the oxidation at constant $10 \mathrm{~V}$. After anodization, the samples were rinsed in distilled water and dried in nitrogen.

Surface morphology was characterized using a Tescan Mira 3 FEG scanning electron microscope equipped with an In-Beam SE detector and Quesant Q-Scope 250 AFM working in tapping mode. The SuperSharp Nanosensors probes were applied for surface scanning. The structure and phase analysis were investigated using Panalytical Empyrean X-ray diffraction (XRD) with $\mathrm{Cu} K_{\alpha}$ radiation. The XPS was applied for surface state characterization. The XPS spectra were measured at room temperature using a SPECS EA 10 PLUS energy spectrometer with $\mathrm{Al} K_{\alpha}$ radiation of $1486.6 \mathrm{eV}$. The energy spectra of the electrons were analyzed by a hemispherical analyzer (full-width at half-maximum $\mathrm{Mg}$ $K_{\alpha}=0.8 \mathrm{eV}$ for $\left.\mathrm{Ag} 3 \mathrm{~d} 5 / 2\right)$. The XPS measurements were conducted following routine backing procedures at $T=150{ }^{\circ} \mathrm{C}$ of the analysis chamber, which made it possible to reach a base vacuum of $5 \times 10^{-11}$ mbar.

The corrosion tests of the materials were done in Ringer's solution $\left(\mathrm{NaCl}: 9 \mathrm{~g} / \mathrm{L}, \mathrm{KCl}: 0.42 \mathrm{~g} / \mathrm{L}, \mathrm{CaCl}_{2}\right.$ : $0.48 \mathrm{~g} / \mathrm{L}$, and $\mathrm{NaHCO}_{3}: 0.2 \mathrm{~g} / \mathrm{L}$ ) using a Solartron 1285 potentiostat working in the potentiodynamic mode with a scan rate of $0.5 \mathrm{mV} / \mathrm{s}$, in the established potential range from -0.7 to $+2.5 \mathrm{~V}$ vs $\mathrm{OCP}$. The electrolyte was kept at a temperature of $37{ }^{\circ} \mathrm{C}$, which simulates body temperature. The counter and reference electrodes were made from Pt. Wetting was analyzed by means of contact angle measurement with an optical Kruss-DSA25 analyzer. A distilled water drop of 1.5 $\mu \mathrm{L}$ volume was used for analysis.

Biocompatibility was tested using normal human osteoblasts Nhost from LONZA (CC-2538). The culture procedure is described elsewhere. ${ }^{[25]}$ For these tests, the Ti plates were sterilized by autoclaving at $120{ }^{\circ} \mathrm{C}$ for 15 minutes and then were separately placed at the bottom of 24-well microplates (NUNC no. 144530). The Nhost cells in static condition were cultured onto each plate at the concentration of 5000 cells/well in $1 \mathrm{~mL}$ culture medium. The cells were cultured at $37^{\circ} \mathrm{C}$ in a 5 pct $\mathrm{CO}_{2}$ incubator of 95 pet humidity for 1 day. Then, the inserts were fixed in 2 pct glutaraldehyde in PBS and stained in 4 pct crystal violet solution. Subsequently, the samples were dehydrated in a series of ethyl alcohol dilutions and subjected to critical point drying; they were then covered with gold for scanning electron microscopy (SEM) observations using Vega Tescan.

\section{RESULTS AND DISCUSSION}

Anodic treatment of pure $\alpha$-type Ti in a mixture of phosphoric and hydrofluoric acids results in the 


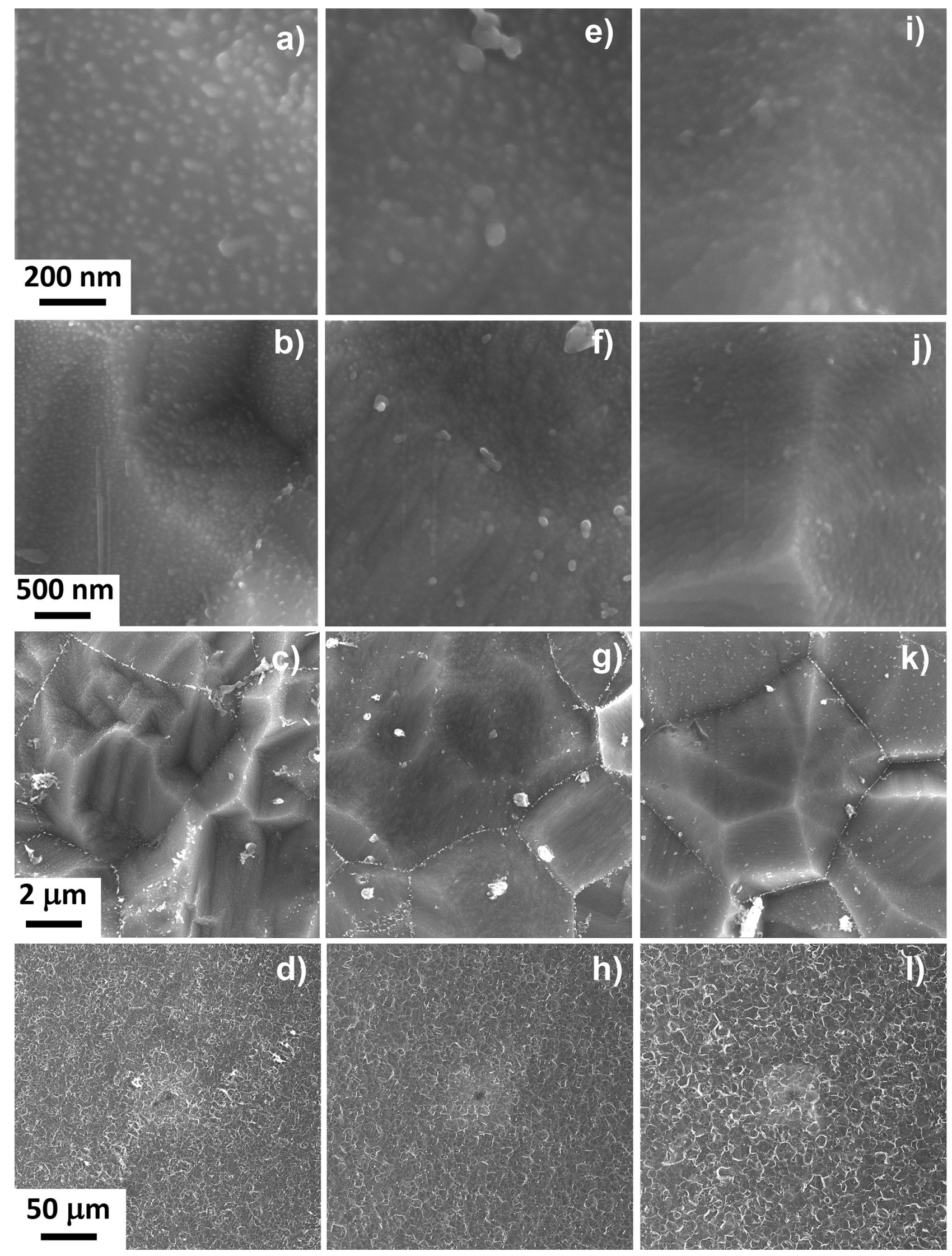

Fig. 1-SEM pictures of Ti surface oxidized for 15 min in $1 \mathrm{M} \mathrm{H}_{3} \mathrm{PO}_{4}$ electrolyte with $(a)$ through $(d) 2$ pct $\mathrm{HF}$, (e) through $(h) 5$ pct $\mathrm{HF}$, and $(i)$ through $(l) 10$ pct HF (different magnifications in columns). 


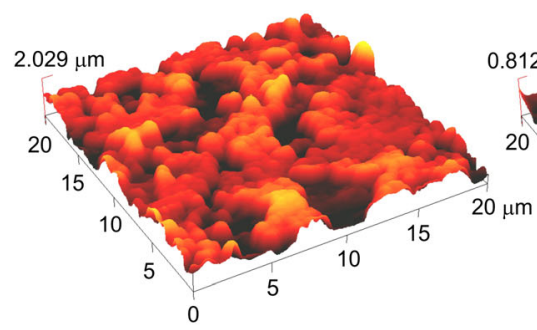

(a)

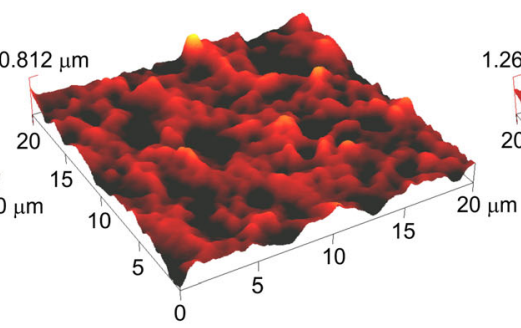

(b)

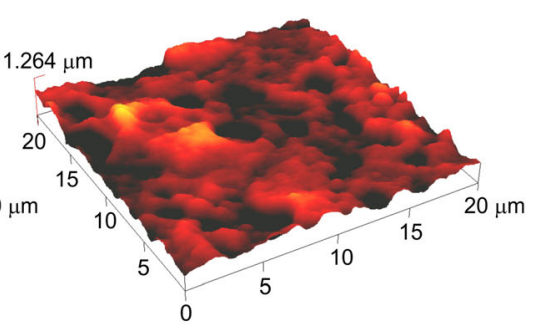

(c)

Fig. 2-AFM pictures of Ti surface oxidized for $15 \mathrm{~min}$ in $1 \mathrm{M} \mathrm{H}_{3} \mathrm{PO}_{4}$ electrolyte with $(a) 2$ pct $\mathrm{HF}$, (b) 5 pct $\mathrm{HF}$, and $(c) 10$ pct $\mathrm{HF}(20 \times 20$ $\mu \mathrm{m}$ scan size).

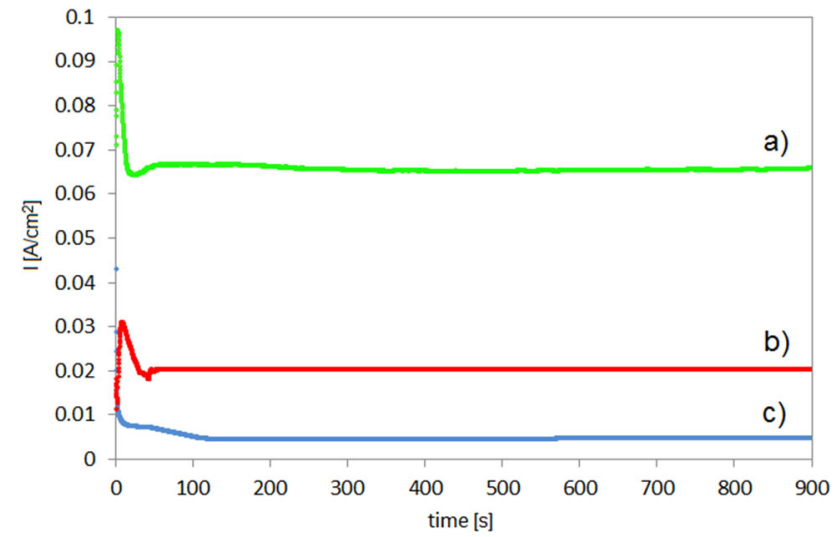

Fig. 3-Current density curves for $1 \mathrm{M} \mathrm{H}_{3} \mathrm{PO}_{4}$ electrolyte with $(a) 2$ pct $\mathrm{HF}$, (b) 5 pct $\mathrm{HF}$, and (c) 10 pct $\mathrm{HF}$ content, recorded for Ti anodically oxidized at $10 \mathrm{~V}$ for $15 \mathrm{~min}$.

formation of a titanium oxide surface layer. The surface morphology is shown in Figures 1 and 2, and due to electrolyte composition, time, and applied potential, the surfaces are partly dissolved, resulting in pit formation.

The Ti surface recorded by SEM for different magnifications shows morphological changes from nano- to macroscale after electrochemical oxidization in $1 \mathrm{M}$ $\mathrm{H}_{3} \mathrm{PO}_{4}$ electrolyte with 2 pct $\mathrm{HF}$ (Figures 1(a) through (d)), 5 pct HF (Figures 1(e) through (h)), and 10 pct HF (Figures 1(i) through (1)). The anodic oxidation leads to formation of surface Ti-oxide through a partial surface dissolution and pit (craters) formation. The surface roughening and pit formation are correlated with grains and their boundaries ((d), (h), and (l)). The formed pits reflect the grains' position (bottom of the pits) and the grain boundaries form hillocks (crater edges) in the surface morphology ((c), (g), and (k); (b), (f), and (j)). The higher HF content enlarged pits in the surface. In the nanoscale ((a), (e), and (i)), the small bright precipitations are visible, more densely packed for oxidation in the electrolyte of a higher HF content ((a), (e), and (i); (b), (f), and (j)). These precipitations in the form of nanoislands, which have a diameter in the range of 10 to $50 \mathrm{~nm}$, participate in the formation of anodic oxide film and can be potentially correlated to an additional oxide or phosphate phase.

The AFM pictures of Ti surface morphology after 15 minutes of anodic oxidation in an electrolyte of $1 \mathrm{M}$ $\mathrm{H}_{3} \mathrm{PO}_{4}$ containing 2, 5, and 10 pct $\mathrm{HF}$ are shown in
Figures 2(a), (b), and (c), respectively. The AFM results show that treatment in electrolytes of various $\mathrm{HF}$ content results in changes of surface morphology, from the spongy type to the well-defined circular-type pores. For 2 and 5 pct HF, the average pore diameter increases from 1 to $2 \mu \mathrm{m}$, respectively. For both cases, maximum pore diameters do not exceed $4 \mu \mathrm{m}$. After Ti anodic oxidation in an electrolyte containing 10 pct HF (c), the pore size maintains an average value close to $2 \mu \mathrm{m}$. The AFM results support and are consistent with those recorded by SEM.

The process undertaken in $1 \mathrm{M} \mathrm{H}_{3} \mathrm{PO}_{4}$ electrolyte containing the addition of higher HF content raises the current density (Figure 3) and, thus, the dissolution rate; however, the surface morphology does not significantly change after treatment in the electrolyte consisting of 5 and 10 pct HF. In the anodic oxidation process, the oxide formation competes with oxide dissolution, especially at higher HF concentration. An increase of HF concentration from 2 to 10 pct results in a faster oxidation reaction. The roughness measured by AFM changes in accordance with anodic oxidation conditions (Table I). Anodic oxidation in $1 \mathrm{M} \mathrm{H}_{3} \mathrm{PO}_{4}+2$ pct $\mathrm{HF}$ gives the highest roughness; however, taking into account the mean height of the profile, the oxidation in $1 \mathrm{M} \mathrm{H}_{3} \mathrm{PO}_{4}+2$ pet $\mathrm{HF}$ and $1 \mathrm{M} \mathrm{H}_{3} \mathrm{PO}_{4}+10$ pet $\mathrm{HF}$, gives a promising surface for tissue in growth and proliferation. In the majority of commercial implants, their surfaces have $\mathrm{Ra}$ in the range 1 to $2 \mu \mathrm{m}$. Too high roughness can adversely affect implant bone interaction, leading to increased ion release, hindered cell adsorption, and increased stress.

The XRD study shows that the Ti provided by the supplier has a layer of native oxide, i.e., anatase- $\mathrm{TiO}_{2}$ (JCPDS No. 01-075-2552); however, Ti substrates (JCPDS No: 01-089-5009) dominate in the entire spectrum due to the low thickness of the native oxide layer (Figure 4(a)). The anodization results in the formation of thicker, albeit porous $\mathrm{TiO}_{2}$; hence, the signal from the Ti substrate (JCPDS No. 01-089-5009) is significant in the entire spectrum.

Treatment in $1 \mathrm{M} \mathrm{H}_{3} \mathrm{PO}_{4}+10$ pct $\mathrm{HF}$ results in formation of more $\mathrm{TiO}_{2}$ (JCPDS No. 01-085-5943 for anatase (204) and 01-006-1890 for rutile (111)) and additional $\mathrm{Ti}\left(\mathrm{HPO}_{4}\right)_{2}$ (d) (JCPDS no. 00-032-1371). The $\mathrm{H}_{3} \mathrm{PO}_{4}$, as the major electrolyte component, provides the phosphorus ions, which are built into the surface. The HF, as the minor electrolyte component, provides 
Table I. Roughness of Anodically Oxidized Ti; for Comparison, Data for Unoxidized Ti

\begin{tabular}{lccc}
\hline Sample & Ra $(\mathrm{nm})$ & $\mathrm{Rq}(\mathrm{nm})$ & $\mathrm{Rc}(\mathrm{nm})$ \\
\hline Ti Before Anodic Oxidation & $25 \pm 2$ & $35 \pm 4$ & $185 \pm 19$ \\
Ti Oxidized in 1M H $\mathrm{PO}_{4}+2$ Pct HF & $284 \pm 36$ & $347 \pm 42$ & $974 \pm 73$ \\
Ti Oxidized in 1M H $\mathrm{PO}_{4}+5$ Pct HF & $128 \pm 24$ & $173 \pm 34$ & $523 \pm 58$ \\
Ti Oxidized in $1 \mathrm{M} \mathrm{H}_{3} \mathrm{PO}_{4}+10 \mathrm{Pct} \mathrm{HF}$ & $185 \pm 32$ & $233 \pm 36$ & $904 \pm 94$ \\
\hline
\end{tabular}

$R a$ arithmetic mean height, $R q$ root mean square deviation, and $R c$ mean height of profile.

the fluorine ions. The formed titanium dioxide-anatase- $\mathrm{TiO}_{2}$ and rutile- $\mathrm{TiO}_{2}$, as well as titanium hydrogen phosphate-Ti( $\left(\mathrm{HPO}_{4}\right)_{2}$, could be useful in the osseointegration process. Negatively charged ions $\left(\mathrm{HPO}_{4}{ }^{2-}\right.$ and $\mathrm{PO}_{4}{ }^{3-}$ complexes) on the surface of titanium oxides contribute to calcium phosphate formation by attracting positively charged $\mathrm{Ca}^{2+}$ ions. ${ }^{[19]}$ Thus, phosphorous content in the surface may act positively on bone nucleation and growth and the osseointegration process, as phosphorous is a significant component of the bone. ${ }^{[9]}$ The enhanced concentration of phosphorous in the surface layer after anodization was also observed by Lee et al. ${ }^{[19]}$

The surface state is very important for biomedical application; thus, the XPS measurements were carried out. The pure cleaned Ti surface was stored in UHV (5 $\times 10^{-11}$ mbar), and the XPS reference spectrum was recorded immediately after 1 minute in UHV (Figure 5(a)). After 2 hours of $\operatorname{UHV}\left(5 \times 10^{-11} \mathrm{mbar}\right)$ conditioning, the Ti surface adsorbed some portion of oxygen atoms from the remaining gases (Figure 5(b)). Some small peaks related to oxygen appear, but Ti-2p peaks are not shifted (Figure 5(b)). This finding means that chemisorption of the previously adsorbed oxygen does not occur.

The different anodic oxidation conditions have no significant effect on the XPS survey spectra (Figure 6). The samples were measured immediately after the transfer to the UHV chamber. In all electrochemically oxidized samples, the O-1s peak is related to oxygen, which is chemically bonded to the $\mathrm{TiO}_{2}$ layer. The presence of oxygen in the surface layer improves the wettability and initial stabilization of the implant. ${ }^{[15]}$ Additionally, an insignificant contamination with carbon was found, probably due to absorption of $\mathrm{CO}_{2}$ from the air.

Results of detailed studies of the positions of the $\mathrm{Ti}-2 \mathrm{p}_{3 / 2}$ and $\mathrm{Ti}-2 \mathrm{p}_{1 / 2}$ peaks for pure $\mathrm{Ti}$ (a) and for oxidized $\mathrm{Ti}\left(1 \mathrm{M} \mathrm{H} \mathrm{PO}_{4}+10\right.$ pct $\left.\mathrm{HF}\right)(\mathrm{b})$ are presented in Figure 7. Peaks of Ti-2p for oxidized samples are significantly shifted (11 and $10.5 \mathrm{eV}$ ) in comparison to clean pure $\mathrm{Ti}$. The position of $\mathrm{Ti}-2 \mathrm{p}_{3 / 2}(459 \mathrm{eV})$ and Ti- $2 \mathrm{p}_{1 / 2}(464.5 \mathrm{eV})$ peaks for the porous anodic oxide layer indicates that stoichiometric $\mathrm{TiO}_{2}$ was formed. The position of Ti-2p peaks and exchangeable fission (5.5 $\mathrm{eV}$ ) is in agreement with the XPS results of the anatase- $\mathrm{TiO}_{2}$ thin films obtained in References [26] and [27].
The valence band of $\mathrm{Ti}$ is affected by anodic oxidation. In all oxidized samples, the maximum of the valence band is significantly shifted to lower binding energy in comparison to clean pure Ti (Figure 8). This shift is enhanced for lower $\mathrm{HF}$ content in electrolyte used for anodic oxidation (a) and (b), whereas an increase in HF content leads to smaller shift (c). The anodic oxidation leads to formation of the $\mathrm{TiO}_{2}$ overlayer with a valence band very similar to that measured for bulk anatase- $\mathrm{TiO}_{2}$. An increase in $\mathrm{HF}$ content leads to an increase of stress and structural disorder of the $\mathrm{TiO}_{2}$ overlayer.

The corrosion resistance was investigated in Ringer's electrolyte, which is a chloride solution. On the basis of polarization curves (Figure 9), corrosion current density $\left(I_{\text {corr }}\right)$, passivation current density $\left(I_{p}\right)$, and corrosion potential $\left(E_{\text {corr }}\right)$ were measured, and these values are shown in Table II. The untreated pure $\mathrm{Ti}$ shows very good corrosion resistance, with corrosion current density $I_{\text {corr }}=3.93 \times 10^{-8} \mathrm{~A} / \mathrm{cm}^{2}$. The anodic oxidation of $\mathrm{Ti}$ in $1 \mathrm{M} \mathrm{H} \mathrm{H}_{3} \mathrm{PO}_{4}+2$ pct $\mathrm{HF}$ electrolyte slightly improves corrosion resistance, resulting in a decrease of $I_{\text {corr }}$ to $2.94 \times 10^{-8} \mathrm{~A} / \mathrm{cm}^{2}$. The Ti anodically oxidized in an electrolyte of higher HF concentration 5 and 10 pct results in a slight decrease of the corrosion resistance with $I_{\text {corr }}=8.57 \times 10^{-8}$ and $1.21 \times 10^{-7} \mathrm{~A} / \mathrm{cm}^{2}$, respectively. Taking into account the changes in the corrosion current density, it should be noted that during anodic oxidation, a porous, rough surface is formed, which finally leads to a larger surface area. The corrosion current density shown is designated with respect to the constant surface area of the nonanodized sample. Thus, in the case of anodized samples, in which the real surface area is larger (due to surface development), the real values of the corrosion current densities are higher. In fact, the corrosion resistance, determined on the basis of this parameter, may be slightly lower in the case of anodized samples, which is usually overlooked in publications. In our previous work, ${ }^{[28]}$ we showed that the surface area gain during anodization can reach a value of about a few percent for low voltage anodization conditions. In all presented oxidation conditions, the $E_{\text {corr }}$ is shifted toward more negative values, which means that the oxidation process of the anodized titanium proceeds more easily. In the case of $E_{\text {corr }}$, this parameter is independent of the surface area; hence, it may be more useful in comparison of the samples' corrosion resistance. Hence, the nonanodized sample of 


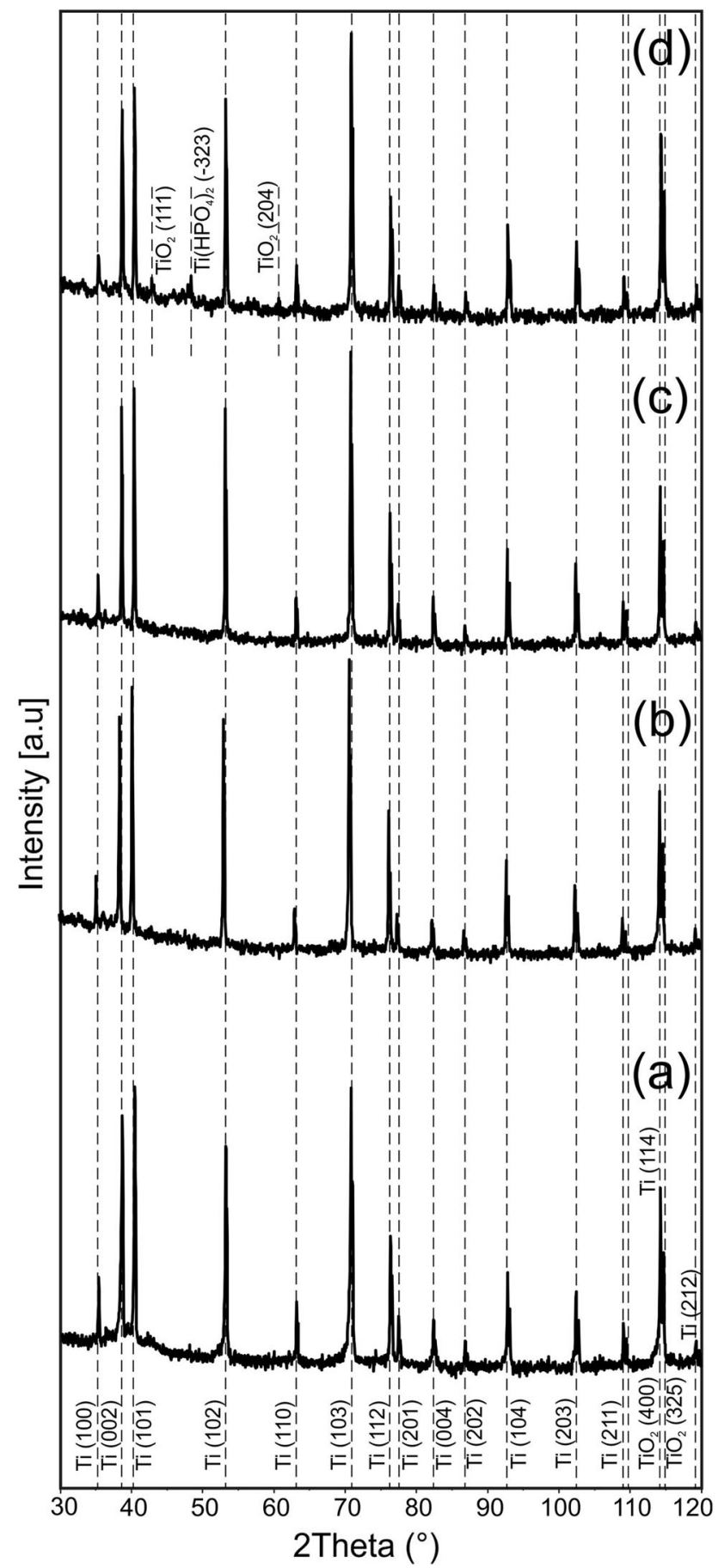

Fig. $4-(a)$ XRD of untreated pure $\mathrm{Ti}$; Ti anodically oxidized in $1 \mathrm{M}$ $\mathrm{H}_{3} \mathrm{PO}_{4}$ electrolyte with $(b) 2$ pct $\mathrm{HF},(c) 5$ pct $\mathrm{HF}$, and (d) 10 pct HF.

the smooth surface shows the best corrosion resistance. One more feature of the polarization curves may be useful for the characterization of corrosion resistance materials. It is a plateau in the anodic potential range. The wider and lower it is, the greater is the material tendency to passivate. However, in determining the $I_{p}$ parameter, one should also bear in mind that the current density calculation was done with respect to the surface area of the nonanodized sample. The passivation current

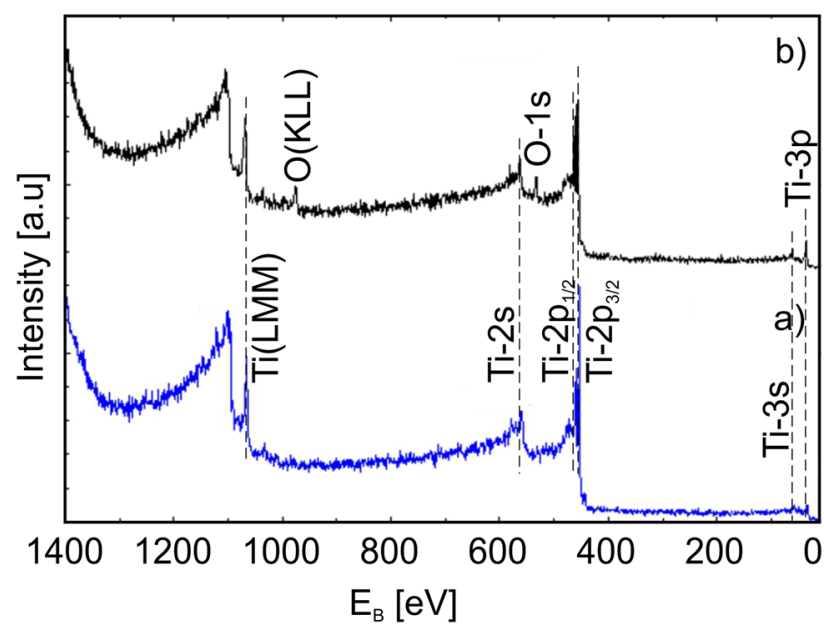

Fig. 5-XPS spectra (Al $K_{\alpha}$ ) of pure Ti after (a) 1 min and (b) $2 \mathrm{~h}$ stored in UHV conditions.

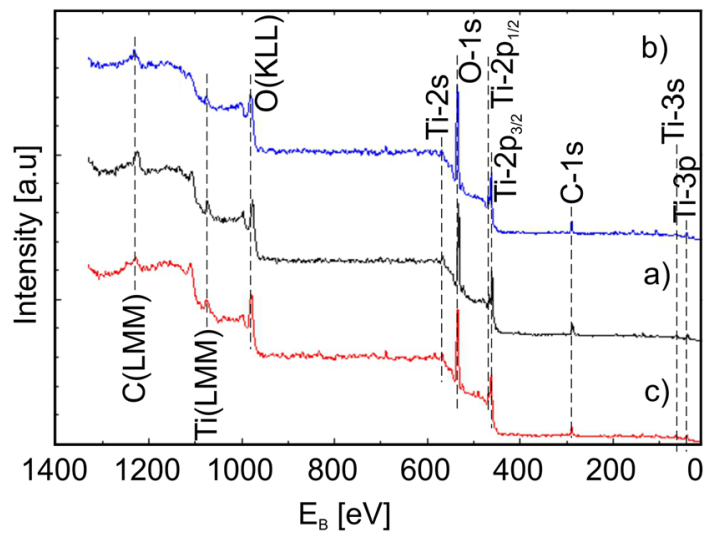

Fig. 6-XPS spectra (Al $K_{\alpha}$ ) of Ti anodically oxidized in $1 \mathrm{M} \mathrm{H}_{3} \mathrm{PO}_{4}$ electrolyte with (a) 2 pct HF, (b) 5 pct HF, and (c) 10 pct HF (data recorded in UHV conditions).

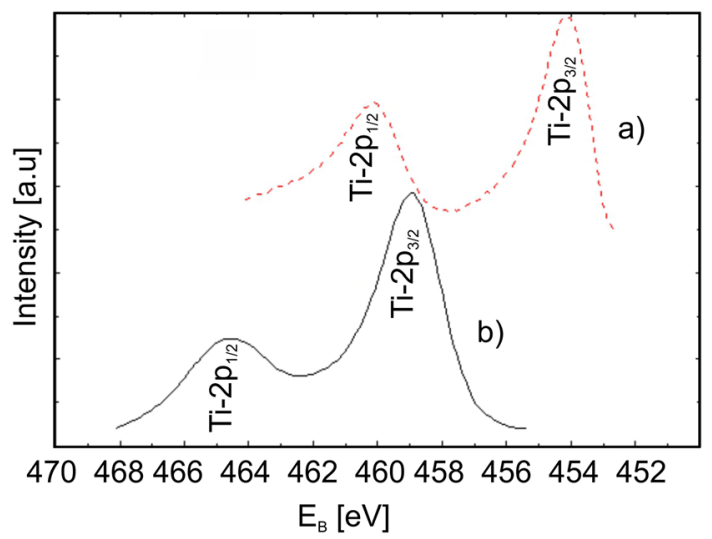

Fig. 7-XPS spectra (Al $\left.K_{\alpha}\right)$ of Ti-2p for $(a)$ pure $\mathrm{Ti}$ and $(b) \mathrm{Ti}$ anodically oxidized at $1 \mathrm{M} \mathrm{H}_{3} \mathrm{PO}_{4}+10$ pct $\mathrm{HF}$ electrolyte (data recorded in UHV conditions).

density $I_{p}$ is lowest in the case of the sample oxidized in $1 \mathrm{M} \mathrm{H}_{3} \mathrm{PO}_{4}+2$ pet HF (Table II). In the anodic oxidation process, shown previously, on the surface, passivating Ti-oxides are formed, which protect the 
material against corrosion attack. Taking into account the shape of the corrosion curves, it is obvious that the anodically oxidized samples have a characteristic current plateau in the passive range (Figures 8(b) through (d)), which was not observed on the untreated $\mathrm{Ti}$ (Figure 9(a)). The shape of the curves and the compro-

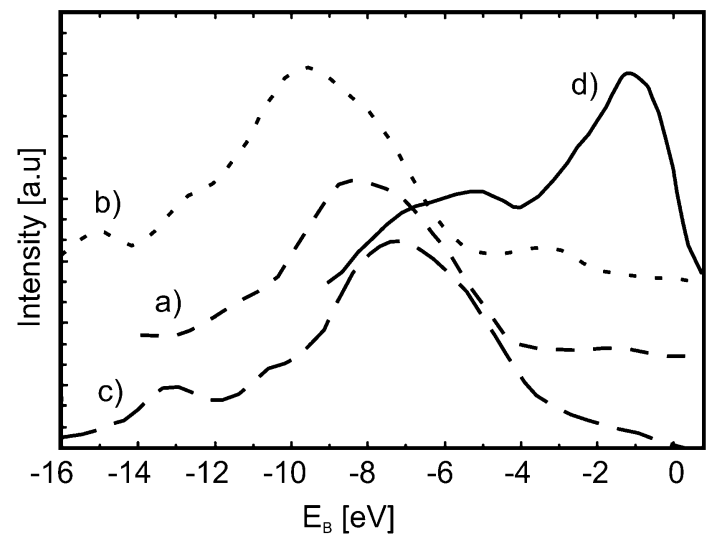

Fig. 8-XPS ( $\mathrm{Al} K_{\alpha}$ ) valence band for Ti anodically oxidized in $1 \mathrm{M}$ $\mathrm{H}_{3} \mathrm{PO}_{4}$ electrolyte with (a) 2 pet $\mathrm{HF}$, (b) 5 pct $\mathrm{HF}$, and (c) 10 pct $\mathrm{HF}$; (d) for comparison, clean pure Ti (data recorded in UHV conditions)

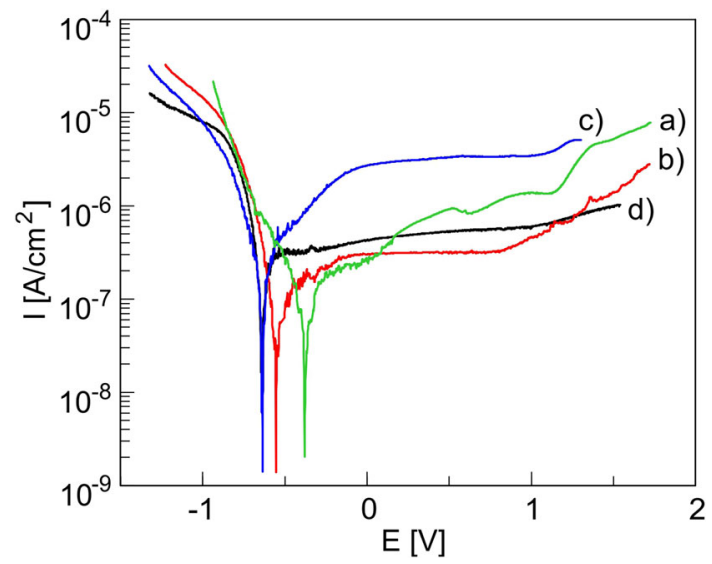

Fig. 9-Corrosion polarization curves of unoxidized $(a) \mathrm{Ti}$; $\mathrm{Ti}$ anodically oxidized in $1 \mathrm{M} \mathrm{H}_{3} \mathrm{PO}_{4}$ electrolyte with $(b) 2$ pct $\mathrm{HF},(c) 5$ pet HF, and (d) 10 pet HF. mise corrosion parameters indicate good passivation and corrosion resistance of the anodically oxidized $\mathrm{Ti}$, especially in the case of Ti electrochemically treated with the $1 \mathrm{M} \mathrm{H}_{3} \mathrm{PO}_{4}+2$ pct $\mathrm{HF}$ electrolyte.

The bioadhesion was tested by means of application of wetting analysis (Table III), showing surface potential toward hydrophilic properties and cell attachment. In all cases of anodic oxidation, the wetting angle decreased in comparison to the untreated $\mathrm{Ti}$, which indicates improved surface hydrophilicity. The best wettability was displayed by the sample anodized in the $1 \mathrm{M} \mathrm{H}_{3} \mathrm{PO}_{4}$ +2 pct HF electrolyte. The osteoblast culture, done using Nhost cells (Figure 10) on selected Ti anodized in the $1 \mathrm{M} \mathrm{H} \mathrm{H}_{3} \mathrm{PO}_{4}+2$ pct $\mathrm{HF}$ electrolyte, shows cell attachment and proliferation that proceeds through formation of extended filopodia spreading through the surface. The rough surface with pits and high wettability acts positively on cell anchoring and proliferation. Osteoblast cells cover nearly 50 pct of the sample surface.

Titanium oxide layer, which covers Ti substrate, plays a key role in corrosion protection and biocompatibility. The surface porosity formed in the anodic oxidation may improve implant stability, especially in the early stage after implantation. Depending on the oxidation process conditions and the oxidation state of the surface, different types of titanium oxides may be formed, among which the $\mathrm{TiO}_{2}$ is thermodynamically most stable. In the crystalline form, $\mathrm{TiO}_{2}$ is found in three varieties: brookite, anatase, and rutile crystal structure. The last two are most useful in Ti surface biofunctionalization. In the anodic oxidation process, the material is subjected to etching (removal of the substrate material), oxidation (growth of the oxide layer), or both of these processes occurring simultaneously, depending on the processing conditions. The proper course of the oxidation process is determined by many factors, such as applied voltage, current density, electrolyte composition, its temperature, $\mathrm{pH}$, or electrolyte mixing. Depending on the applied voltage, continuous, ${ }^{[29]}$ porous, ${ }^{[17,30]}$ or nanotube oxide layers $^{[17,31-33]}$ may be formed on the titanium surface, which are characterized by different thickness, phase composition, morphology, and physicochemical properties. By designing the appropriate process conditions, it is possible to properly biofunctionalize the surface for implant applications. Quite a significant limitation of the anodic oxidation process, in which the porous

Table II. Corrosion Current Density $\left(I_{\text {corr }}\right)$, Passivation Current Density $\left(I_{p}\right)$, and Corrosion Potential $\left(E_{\text {corr }}\right)$ for the Studied Materials

\begin{tabular}{lcrr}
\hline Sample & $I_{\text {corr }}\left(\mathrm{A} / \mathrm{cm}^{2}\right)$ & $E_{\text {corr }}(\mathrm{V})$ & $I_{p}\left(\mathrm{~A} / \mathrm{cm}^{2}\right)$ \\
\hline Ti Before Anodic Oxidation & $3.93 \pm 0.16 \times 10^{-8}$ & $-0.38 \pm 0.01$ & $8.38 \pm 0.33 \times 10^{-7}$ \\
Ti Oxidized in 1 $\mathrm{M} \mathrm{H}_{3} \mathrm{PO}_{4}+2 \mathrm{Pct} \mathrm{HF}$ & $2.93 \pm 0.09 \times 10^{-8}$ & $-0.55 \pm 0.01$ & $3.14 \pm 0.06 \times 10^{-7}$ \\
Ti Oxidized in 1 $\mathrm{M} \mathrm{H}_{3} \mathrm{PO}_{4}+5 \mathrm{Pct} \mathrm{HF}$ & $8.57 \pm 0.04 \times 10^{-8}$ & $-0.63 \pm 0.01$ & $3.39 \pm 0.13 \times 10^{-6}$ \\
Ti Oxidized in 1 $\mathrm{M} \mathrm{H}_{3} \mathrm{PO}_{4}+10 \mathrm{Pct} \mathrm{HF}$ & $1.21 \pm 0.03 \times 10^{-7}$ & $-0.64 \pm 0.01$ & $5.35 \pm 0.18 \times 10^{-7}$ \\
\hline
\end{tabular}


Table III. Wetting Analysis of Anodically Oxidized Ti

Ti Before Anodic Oxidation

Ti Oxidized in $1 \mathrm{M} \mathrm{H}_{3} \mathrm{PO}_{4}+2 \mathrm{Pct} \mathrm{HF}$

Ti Oxidized in $1 \mathrm{M} \mathrm{H}_{3} \mathrm{PO}_{4}+5 \mathrm{Pct} \mathrm{HF}$

Ti Oxidized in $1 \mathrm{M} \mathrm{H}_{3} \mathrm{PO}_{4}+10$ Pct $\mathrm{HF}$
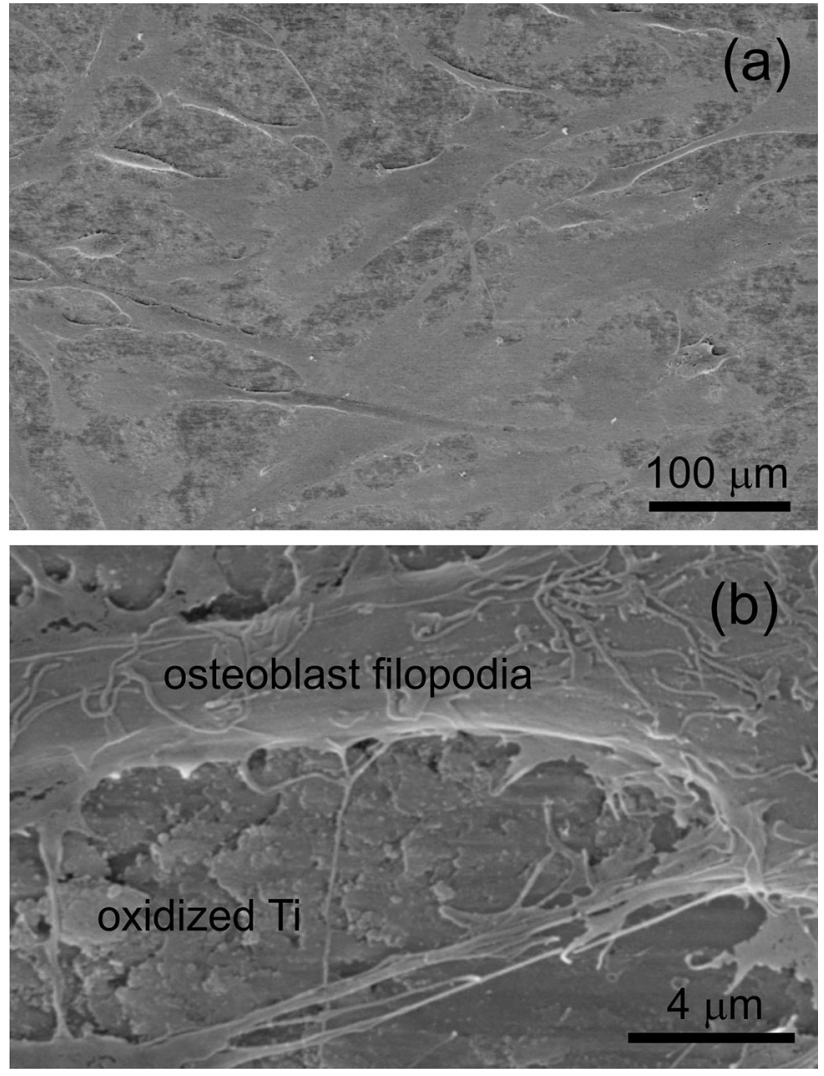

Fig. 10 - Osteoblast cells after 1 day culture proliferated on the $\mathrm{Ti}$ surface anodically oxidized in $1 \mathrm{M} \mathrm{H}_{3} \mathrm{PO}_{4}+2$ pct $\mathrm{HF}$ electrolyte; (a) and (b) different magnifications.

structure is formed, is the pore diameter. As a rule, it does not exceed a dozen or so micrometers. Research conducted by Webster and Ejiofor ${ }^{[22]}$ shows that small surface nanofeatures also support bone growth. Anodic oxidation not only leads to formation of porous titanium oxide, but also to formation of surface $\mathrm{TiO}_{2}$ nanotubes or nanofibers. These surface nano-objects cause a good biological response of the tissue, e.g., better cell adhesion and differentiation. The growth of nanotubes proceeds in a few stages, one of which is the formation of nanopores. ${ }^{[34]}$ The formation of $\mathrm{TiO}_{2}$ surface nanotubes needs to maintain a narrow range of technological parameters to their growth and to prevent the delamination effect, ${ }^{[35]}$ which limits their application. Hence, a rather more common result of anodic oxidation is formation of an oxide porous surface layer, which is easier to obtain and apply. In most cases of titanium anodic oxidation, the use of phosphorus-containing electrolytes makes it possible to introduce this element into the implant surface layer (e.g., $\mathrm{Ti}\left(\mathrm{HPO}_{4}\right)_{2}$ in Figure 4(d)) and nucleation of calcium phosphates when soaking the material in the SBF solution. ${ }^{[19]}$ The addition of $\mathrm{HF}$, which increases the current density, ${ }^{[36]}$ accelerates dissolution and enhances changes in substrate morphology. ${ }^{[30]}$ However, the fluorine ions that form $\mathrm{TiF}_{6}{ }^{2-}$ complexes dissolve titanium oxides. Thus, the dissolution process limits the thickness of the porous oxide layer. ${ }^{[37]}$ The tailored, porous, well wettable anodic titanium oxide surface layer should guarantee good and quick osseointegration with bone, which is obviously not provided by the native smooth titanium oxide layer. ${ }^{[19]}$ Among many surface treatment technologies, those based on electrochemical ones play a most important role in $\mathrm{Ti}$ biofunctionalization; hence, the wide interest in this area of research.

\section{SUMMARY}

In this work, electrochemical anodic oxidation as biofunctionalization of the titanium surface was studied. It was shown that the Ti surface after anodic oxidation in an electrolyte composed of $\mathrm{H}_{3} \mathrm{PO}_{4}$ and $\mathrm{HF}$ is covered mainly by the anatase- $\mathrm{TiO}_{2}$; however, traces of $\mathrm{Ti}\left(\mathrm{HPO}_{4}\right)_{2}$ can support osseointegration. The best surface state of $\mathrm{Ti}$, with the most promising properties for hard tissue applications, was achieved in oxidation in $1 \mathrm{M} \mathrm{H}_{3} \mathrm{PO}_{4}+2$ pct $\mathrm{HF}$ for 15 minutes, whereas an increase in $\mathrm{HF}$ content leads to a slight decrease in $\mathrm{Ti}$ surface potential for these applications. The sample shows a highly porous oxide morphology, the highest corrosion resistance and wettability reflecting high bioadhesion and osteoblast cell attachment and proliferation.

\section{ACKNOWLEDGMENT}

This work has been financed by the Ministry of Education and Science in Poland under the SBAD project.

\section{CONFLICT OF INTEREST}

The authors declare that they have no conflict of interest. 


\section{OPEN ACCESS}

This article is licensed under a Creative Commons Attribution 4.0 International License, which permits use, sharing, adaptation, distribution and reproduction in any medium or format, as long as you give appropriate credit to the original author(s) and the source, provide a link to the Creative Commons licence, and indicate if changes were made. The images or other third party material in this article are included in the article's Creative Commons licence, unless indicated otherwise in a credit line to the material. If material is not included in the article's Creative Commons licence and your intended use is not permitted by statutory regulation or exceeds the permitted use, you will need to obtain permission directly from the copyright holder. To view a copy of this licence, visit http://creat ivecommons.org/licenses/by/4.0/.

\section{REFERENCES}

1. M Niinomi: Mater. Sci. Eng. A, 1998, vol. 243, pp. 231-36.

2. DM Brunette, $\mathrm{P}$ Tengvall, $\mathrm{M}$ Textor, and $\mathrm{P}$ Thomsen: Titanium in Medicine: Material Science, Surface Science, Engineering, Biological Responses and Medical Applications, Springer, Berlin, 2001.

3. S Fujibayashi, M Neo, HM Kim, T Kokubo, and T Nakamura: Biomaterials, 2004, vol. 25, pp. 443-50.

4. M Niinomi and M Nakai: Int. J. Biomater., 2011, vol. 2011, pp. $1-10$.

5. C-L Yang, F-L Chen, and S-W Chen: Mater. Chem. Phys., 2006, vol. 100, pp. 268-274.

6. W Simka, M Kaczmarek, A Baron-Wiecheć, G Nawrat, J Marciniak, and J Żak: Electrochim. Acta, 2010, vol. 55, pp. 2437-441.

7. YT Sul, CB Johansson, Y Jeong, and T Albrektsson: Med. Eng. Phys., 2001, vol. 23, pp. 329-46.

8. YT Sul: Biomaterials, 2003, vol. 24, pp. 3893-3907.

9. SE Kim, JH Lim, SCh Lee, S-C Nam, H-G Kang, and J Choi: Electrochim. Acta, 2008, vol. 53, pp. 4846-51.

10. J Jakubowicz, G Adamek, and MU Jurczyk: Mater. Charact., 2012, vol. 70, pp. 55-62.

11. K Das, S Bose, and A Bandyopadhyay: Acta Biomater., 2007, vol. 3, pp. 573-85.

12. S Ban, Y Iwaya, H Kono, and H Sato: Dent. Mater., 2006, vol. 22, pp. $1115-120$.

13. P Huang, K Xu, and Y Han: J. Mater. Sci. Mater. Med., 2007, vol. 18 , pp. $457-63$.
14. HM Kim, F Miyaji, T Kokubo, and T Nakamura: J. Biomed. Mater. Res., 1996, vol. 32, pp. 409-417.

15. Y Xie, J Zuo, B Zhou, L Ma, ZM Yu, Q Wei, and ZG Tang: Mater. Lett., 2016, vol. 176, pp. 74-77.

16. QY Zhang, Y Leng, and RL Xin: Biomaterials., 2005, vol. 26, pp. 2857-65.

17. JM Macak, K Sirotna, and P Schmuki: Electrochim. Acta, 2005, vol. 50, pp. 3679-84.

18. C Yao and TJ Webster: J. NanoSci. NanoTech., 2006, vol. 6, pp. 2682-92.

19. J-H Lee, S-E Kim, Y-J Kim, C-S Chi, and H-J Oh: Mater. Chem. Phys., 2006, vol. 98, pp. 39-43.

20. G Adamek, MU Jurczyk, and J Jakubowicz: J. Biomater. Tiss. Eng., 2011, vol. 1, pp. 101-109.

21. S Bauer, S Kleber, and P Schmuki: Electrochem. Commun., 2006, vol. 8, pp. 1321-25.

22. TJ Webster and JU Ejiofor: Biomaterials, 2004, vol. 25, pp. 4731-39.

23. TJ Webster, C Ergun, RH Doremus, RW Siegel, and R Bizios: Biomaterials, 2000, vol. 21, pp. 1803-10.

24. TJ Webster, RW Siegel, and R Bizios: Biomaterials, 1999, vol. 20, pp. 1221-27.

25. K Jurczyk, G Adamek, MM Kubicka, J Jakubowicz, and M Jurczyk: Materials, 2015, vol. 8, pp. 1398-12.

26. G Liu, W Jaegermann, J He, V Sundström, and L Sun: J. Phys. Chem., 2002, vol. 106, pp. 5814-819.

27. S-Z Chen, P-Y Zhang, W-P Zhu, L Chen, and SM Xu: Appl. Surf. Sci., 2006, vol. 252, pp. 7532-38.

28. JK Koper and J Jakubowicz: J. Biomater. Tiss. Eng., 2014, vol. 4, pp. 459-64.

29. H-J Oh, J-H Lee, Y Jeong, Y-J Kim, and C-S Chi: Surf. Coat. Technol., 2005, vol. 198, pp. 247-52.

30. J Jakubowicz: Electrochem. Commun., 2008, vol. 10, pp. 735-39.

31. Q Cai, L Yang, and Y Yu: Thin Sol. Films, 2006, vol. 515, pp. 1802-806.

32. Q Cai, M Paulose, OK Varghese, and CA Grimes: J. Mater. Res., 2005, vol. 20, pp. 230-36.

33. JM Macak, H Tsuchiya, S Berger, S Bauer, S Fujimoto, and P Schmuki: Chem. Phys. Lett., 2006, vol. 428, pp. 421-25.

34. GA Crawford and N Chawla: Acta Mater., 2009, vol. 57, pp. 854-67.

35. Y Yang, X Wang, and L Li: Mater. Sci. Eng. B, 2008, vol. 149, pp. $58-62$.

36. H Tsuchiya, JM Macak, L Taveira, E Balaur, A Ghicov, K Sirotna, and P Schmuki: Electrochem. Commun., 2005, vol. 7, pp. $576-80$.

37. R Beranek, H Hildebrand, and P Schmuki: Electrochem. SolidState Lett., 2003, vol. 6, pp. B12-14.

Publisher's Note Springer Nature remains neutral with regard to jurisdictional claims in published maps and institutional affiliations. 